\title{
Trust in the News: A Digital Labelling Solution for Journalistic Contents
}

\author{
Zhan Liu ${ }^{\text {* }}$ \\ (iD) 0000-0003-3367-3204
}

Matthieu Delaloye 1

(iD) 0000-0002-2428-0241

Nicole Glassey Balet ${ }^{1}$

(iD) 0000-0003-3268-8375

Sébastien Hersant ${ }^{2}$

(iD) 0000-0001-9956-1278

\section{Frédéric Gris ${ }^{2}$}

(iD) $0000-0003-4733-2101$

\section{Laurent Sciboz ${ }^{1}$}

\section{(iD) 0000-0003-0122-5351}

\author{
${ }^{1}$ University of Applied Sciences and Arts Western Switzerland (HES-SO Valais-Wallis), SWITZERLAND \\ 2 ESH Médias, SWITZERLAND \\ * Corresponding author: zhan.liu@hevs.ch
}

Citation: Liu, Z., Delaloye, M., Glassey Balet, N., Hersant, S., Gris, F., \& Sciboz, L. (2022). Trust in the News: A Digital Labelling Solution for Journalistic Contents. Online Journal of Communication and Media Technologies, 12(2), e202207. https://doi.org/10.30935/ojcmt/11528

\section{ARTICLE INFO}

Received: 25 Aug 2021

Accepted: 5 Dec 2021

\begin{abstract}
Trust has long been considered an important factor that affects the relation between people and news. However, with the increasing amount of information online, as well as new digital tools and services, this relation has changed, everyone can create content, anytime and anywhere. Therefore, being able to identify and distinguish reliable sources of information online becomes a challenge for the public. In this paper, we focus on providing a digital labelling solution for journalistic contents to enhance the readers' trust in the media by using design science method. Focus group interviews were conducted to examine reader's trust perceptions in news contents and their opinions on the trust labelling mechanism. Discussion results helped us to build a list of trust indicators which were used in our labelling distribution system for news content evaluation. Finally, we designed and developed an intermedia certification system to distribute the labelling on trust news contents. Obtained evaluation results confirmed the utility of our system and provided support to readers in identification of the reliable news content.
\end{abstract}

Keywords: digital labelling, trust indicator, news content, journalist self-assessment, readerships perceptions, news article quality

\section{INTRODUCTION}

Trust is one of the most important factors affecting the relation between people and news. However, with the increasing amount of information online, as well as new digital tools and services, this relation has changed, largely by narrowing the distance between the media industries and their audiences. This has, in turn, changed consumer behaviours and expectations. For example, social media have enabled everyone to create content, anytime and anywhere. However, at the same time, it is also possible for unverified information derived from untraceable sources to spread quickly. In some ways, social network platforms have 
democratized news more than ever before, and as a result, the public is exposed to false news that scrolls across their screens every day. As a consequence of this new paradigm, being able to identify and distinguish reliable sources of information online becomes a challenge for the public.

Trust in the news is an increasingly popular topic in today's news media environment. It is perceived sometimes that powerful people who want to promote their personal agendas rather than serve the public control the media (Newman \& Fletcher, 2017). The low public trust in the media environment makes it possible for dangerous false narratives to take root in all sectors of society, especially during the emergent crises (Knight Foundation, 2020). Therefore, having the audience's trust is vital to journalism's core value. This is simply because credibility of the media brand is an important feature that affects readers' trust in news organizations. On the one hand, the characteristics of digital news have established an equal relationship between journalists and readers, readers can make their own opinions and comments on the reporter's article at any time (Lewis et al., 2014). On the other, news organizations have integrated different mechanisms to control content quality both in online and offline news reports, which include the review of the journalists' reputations, and the algorithms that detect false news automatically (Buntain \& Golbeck, 2017; Liu et al., 2019; Ozbay \& Alatas, 2020; Shabani \& Sokhn, 2018; Shu et al., 2017; Wang, 2017).

Interestingly, most people have confidence in their own ability to identify false news stories and believe that the news that they share with others is factual. According to a Pew Research Center study (Barthel et al., 2016), most Americans (84\%) are very confident in their own ability to identify false news stories. However, $64 \%$ of those surveyed said that false news has left them confused about the basic facts of current events. This contrast may be explained by the third person effect theory, which asserts that "People will tend to overestimate the influence that mass communications have on the attitudes and behaviour of others" (Davison, 1983, p. 3). A recent study (Liu et al., 2020) showed the way people in Switzerland trust and consume coronavirus-related news during the COVID-19 pandemic. Based on the analysis of 442 participants assigned randomly, only $24.7 \%$ of them were able to identify false news in coronavirus statements correctly. Their analysis demonstrated that male respondents and those with a higher education are more likely to be able to discriminate between accurate and false news. Obviously, it is still difficult to rely on people's own ability to distinguish false news in the context of the rapid spread of misinformation. As the digital world ease the connection between distant people, the trust needed to distinguish a reliable information source from the rest is more complex to make tangible. Making the public attentive to the source seems to be a goal for modern medias.

News labels provide readers with information that helps them interpret the information presented and, thereby, affects the content's perceived credibility (Peacock et al., 2020). Driven by the news label's potential to help restore trust in the news media, lannucci (2017) examined 25 local newspapers and 24 news websites in the U.S. to determine the effects on the readership of labelling journalistic content. Their findings are significant, because journalists are focusing on article labels as an important way to address the decline in trust of the news media. Moreover, Krouwer et al.'s (2020) experimental research has shown that providing additional details about the types of news content can increase credibility relative to more standard disclosures via perceived transparency (e.g., opinion and sponsored content). Their study also demonstrated that readers were more interested in the articles with an opinion label than sponsored label, because they may expect that sponsored content will be more prone to advertising information than opinion news content. As a result, people may ascribe less credibility to the sponsored-labelled article, and in contrast, more credibility to the articles with opinion and original labels.

In this study, we focus on providing a digital labelling solution for journalistic contents to enhance the readers' trust in the media. To accomplish this goal, we first conducted six focus-group interviews to examine reader's trust perceptions in news contents and their opinions on the trust labelling mechanism. Then, we constructed a list of trust indicators based on interviews discussions. These indicators can not only be used to assess the credibility of news organizations and contents, but also to provide guidelines for designing the trust labelling. Finally, we designed an intermedia certification system to demonstrate how it could be used in a labelling distribution process. Our system was tested by journalists and editors, and to ask them for their opinions and suggestions. In this study, we provided answers to the following research questions: 
1. Does providing a label promote the quality of digital journalistic online text-based content, and/or increase the readership's trust?

2. What method(s) could be used to develop indicators to certify journalistic content's quality?

3. What is the most optimal approach to deploy an intermedia certification system both at the regional and national levels?

The remainder of this paper is organized as follows: Related work is summarized first. The methodology is then presented, which describes the sample, data collection process, and the certification system's development. Next, the focus groups' discussions on trust indicators are presented. After that we describe the process of developing the application and its evaluation. Finally, we conclude this study and discuss directions for future work.

\section{RELATED WORKS}

There is increasing interest on different institutions' part to address the trust problem in news. Reporters without Borders launched the Journalism Trust Initiative (JTI) in response to the concern that a decline in trust in journalism is ultimately leading to a decline in journalists' safety and security (Boulay, 2018). This initiative developed the policies of transparency, verification, editorial independence, and compliance to evaluate the media's quality. During the same period, Google announced a new online service, the Google News Initiative (GNI), to fight false news, misinformation, and contentious breaking stories (Deschamps, 2018). The project planned to spend $\$ 392$ million to develop and strengthen high-quality information in journalists' contents to achieve sustainable growth. Its goal is to stop the spread of misinformation, help readers access quality publications easily, and finally, explore the way journalism can better signal trustworthiness to consumers. The credibility of an online platform is built on the quality of its content. Search engines as well as social networks therefore have everything to gain by building trust in their content.

With a similar goal to promote journalism's quality, some researchers have sought to define indicators to measure the quality of journalists' contents. The Trust Project emerged from a collaboration led by Lehrman (2016), which included nearly all famous publishers around the world, such as The Economist, The Washington Post, Germany's Deutsche Presse-Agentur (DPA), The Globe and Mail, and the Independent Journal Review. The author conducted in-depth interviews with news consumers to understand what people value in news contents, and more importantly, why and when they trust them. This project identified a total of 27 indicators, which were classified into eight categories, including best practices, author expertise, type of work, citations and references, methods, locally sourced, diverse voices, and actionable feedback. These indicators are believed to increase news openness and transparency. Zhang et al. (2018) outlined a process with which to define indicators of credibility and validate them through data from the Credibility Coalition-a research community_composed of journalists, researchers, academics, students, policymakers, technologists, and engaged non-specialists. They provided credibility indicators that anyone can use easily to reduce misinformation and promote online information quality.

Another set of studies focused on technical tools to analyse news sites' reliability and general trustworthiness. For example, NewsGuard (Bennett \& Brandt, 2019; Stelter, 2018) was designed to evaluate and rate news websites' reliability. The evaluation results were based on nine criteria accepted widely by journalism standards. For each news website, NewsGuard's journalists write a label review explaining the way they decided whether the site passed or failed each criterion and giving background on the publication and its history. Similar to NewsGuard, the Media Bias Fact Check is an independent online media outlet researchers and journalists maintain that contains one of the most comprehensive lists of false and mainstream news sites (Van Zandt, 2021). Previous researchers have used their publications widely to construct a ground-truth dataset (Bozarth \& Budak, 2020; Dinkov et al., 2019; Norregaard et al., 2019; Starbird, 2017; Stefanov et al., 2020). Another online tool, Transparency Journalism, allows readers to understand the informative process that the journalist has followed to produce a given news item. A transparency map is constructed to show the measurement and analysis of eight Indicators of Editorial Transparency used to evaluate the news contents' quality and guarantee the greatest possible traceability of the information it publishes (Publico, 2018). 
As the initiatives are numerous, they don't always fit the Swiss media scene. The JTI project is dedicated to countries with political instability; the GNI project might be biased for political reasons as Google does not share the same point of view with some governments regarding the remuneration desired by some local medias, and the Trust Project lack of visibility in Switzerland and would need to be heavily promoted before generating benefits. Therefore, unlike the existing studies (e.g., Bennett \& Brandt, 2019; Publico, 2018; Van Zandt, 2021), we focused on news reliability not only at the media level, but also with respect to each item of journalism content. In addition, there is not a complete and effective trust indicator list from existing research to help us evaluate the credibility of news content. We attempted to fill the research gap in this study and proposed a trust labelling distribution system to describe its availability.

\section{METHODOLOGY}

In this study, we followed the design science research framework methodology (Hevner et al., 2004) to design and develop the labelling application. As illustrated in Figure 1, we began to identify the readers' trust perceptions in news contents that include a digital labelling solution's effect on the readership's confidence and exceptions to ensure the goal of the study's relevance to the focus group discussions. We then examined the requirements from the research's contextual environment and described our application through environmental field testing. To achieve this goal, we worked with experienced editors and journalists to evaluate whether the existing system could be integrated with new functions. Moreover, we drew upon an existing application programming interface and added newly generated knowledge to the knowledge base. The central design cycle focused on constructing and evaluating the prototype and processes through qualitative evaluation methods. Accordingly, we conducted individual interviews with journalists and editors to assess the application's functionality and usefulness. These were conducted iteratively in parallel with software development to ensure that their suggestions were incorporated in the design.

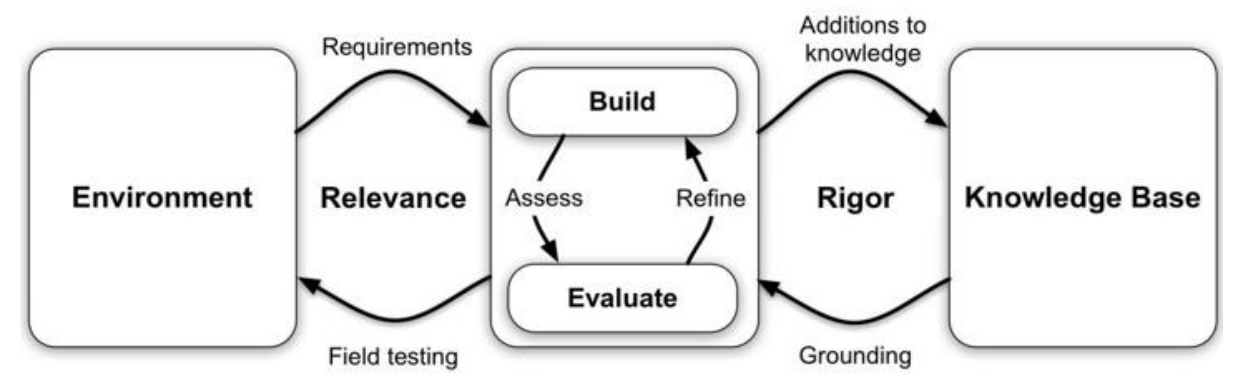

Figure 1. Information systems research framework (Hevner et al., 2004)

\section{Sample Description}

Six focus group interviews were conducted with participants from different age ranges and backgrounds. In total, 24 people, 13 females and 11 males from the French-speaking region of Switzerland, took part in this study. All subjects ranged in age between 21 and 79 years old, with an average age of 50.1 years. Most (58\%) have a university degree, $38 \%$ a high school degree, and the remaining $4 \%$ an elementary school diploma. Among the participants, 37\% indicated that they subscribed to a French-speaking daily newspaper. The remaining 63\% did not, but they obtained information from a mobile application or social media on a daily basis. Table 1 provides a summary of the participants' demographic and geographic characteristics.

During each focus group interview, we asked questions about participants' news consumption behaviours, as well as perceptions of, and experiences with, labels and journalistic contents. For the sake of clarity, focus groups are a form of group interview in which the focus of investigation is on participants' communication within the group rather than on alternating questions and responses between the researcher and respondents. They have been proven an effective research technique to investigate individuals' perceptions and attitudes, as well as explore the reasons for them. Hence, we believe that it is an appropriate research method to achieve our objective. 
Table 1. Participants' demographics $(\mathrm{N}=24)$

\begin{tabular}{|c|c|c|c|}
\hline & & Number & Percentage \\
\hline \multicolumn{4}{|l|}{ Gender } \\
\hline & Male & 11 & $54 \%$ \\
\hline & Female & 13 & $46 \%$ \\
\hline \multicolumn{4}{|l|}{ Age } \\
\hline & $18-25$ & 6 & $25 \%$ \\
\hline & $26-45$ & 6 & $25 \%$ \\
\hline & $46-65$ & 6 & $25 \%$ \\
\hline & 66 and over & 6 & $25 \%$ \\
\hline \multicolumn{4}{|l|}{ Education } \\
\hline & Compulsory education & 1 & $4 \%$ \\
\hline & Highschool graduate & 9 & $38 \%$ \\
\hline & University degree & 14 & $58 \%$ \\
\hline \multicolumn{4}{|l|}{ Job level } \\
\hline & Employee & 5 & $21 \%$ \\
\hline & Independent & 8 & $33 \%$ \\
\hline & Manager & 2 & $8 \%$ \\
\hline & Unemployed & 9 & $38 \%$ \\
\hline \multicolumn{4}{|l|}{ Subscriber } \\
\hline & Daily newspaper & 9 & $37 \%$ \\
\hline & Non-daily newspapers & 15 & $63 \%$ \\
\hline
\end{tabular}

\section{Data Collection and Analysis}

The objective of data collection was to evaluate the readership's experiences, needs, expectations, and representations, particularly to identify the specific and complex issue of readership confidence in the media to measure a label's effect on journalistic content. To achieve this objective, the participants were subjected to a series of semi-directed questions and a reflective User-Centred Design (Abras et al., 2004) process. In addition, we gave them four article mock-ups with different labels to stimulate debate about the process of building confidence. This step allowed us to identify which label format may have the most optimal effects on the readership.

Each focus group session was held in a relaxing meeting place (e.g., newspaper media conference room). The interviews lasted 90 minutes on average and were accompanied by a moderator and an observer. All conversations were recorded on camera and transcribed by two researchers to perform data triangulation. We adapted and applied a framework analysis method in the analysis process, which may be organized in five steps (Lacey \& Luff, 2007; Srivastava \& Thomson, 2009):

1. Familiarization: Achieved by reading the data collected during interviews with participants. In this step, two researchers listened to and transcribed the audio recordings to obtain an overview of the data collected.

2. Identifying a thematic framework: Achieved by identifying a set of variables that were developed both from a priori issues and those that emerged from the first cluster. Two researchers reviewed all transcripts carefully and created separate categories. They then had a face-to-face meeting to compare and combine these categories. Some comments were placed in more than one category, whilst others that lacked sufficient significance were excluded.

3. Indexing: This is regarded more commonly as coding in other qualitative analysis approaches, as it is the process of using codes to identify specific pieces of data. By combining the existing theoretical foundations, the same two researchers were able to work together to rearrange the categories identified during the second step.

4. Charting: Achieved by placing the headings and subheadings drawn from previous stages in charts that can be read easily across the entire dataset.

5. Mapping and interpretation: The final stage involved searching for patterns, associations, concepts, and explanations. 


\section{DISCUSSIONS ON TRUST INDICATORS}

In this section, we present the results obtained from the focus group discussions. We constructed a list of trust indicators as standards to measure the quality of journalists' contents. Moreover, we used these indicators in building our trust labelling distribution system in the next section.

We classified the focus groups' discussion into five themes, as shown in Figure 2, each of them consisted of several categories. These results allowed us to evaluate participants' consumption behaviour, their perceptions of both traditional and digital medias. More importantly, we were also able to identify elements that increased readership confidence. Finally, readers' perceptions of different labelling formats are discussed in this section.

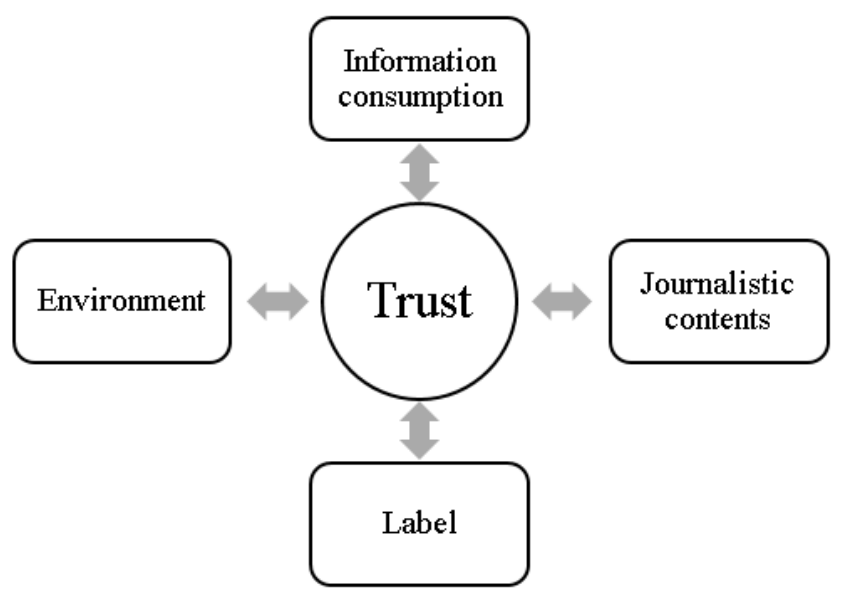

Figure 2. Results of readerships' perceptions from focus group discussions

The journalism environment was the first theme that appeared during most of the discussions. Generally, the participants stated that they trusted Swiss journalistic contents and believed that false news was rare in Switzerland. However, as social media are altering the perception of reality, sometimes they had difficulty distinguishing information received from different channels. Concerns about information consumption differed between the groups of adults older than 30 and young people 30 years old or younger. The older group had general interests in the press, followed the news nearly every day, and declare being able to distinguish and curate by themselves reliable sources of information. In contrast, younger people tended to gather information from social networks when needed, often via their mobile phones, and identify a trustworthy person who provides them with information. Further, they were unwilling to pay for journalistic content because of their limited budgets. However, the lack of authentication of social media content made it difficult for them to distinguish between factual and false news. Our focus group also showed concerns about journalistic contents. This theme focused on the discussion of the contents' originality. Essentially, they preferred to read original content, particularly journalists' commentary stories. The journalist's reputation has a significant positive effect on them, and half of the participants believed that a well-known journalist served as a more trustworthy source than a famous media brand. However, young people did not see it in this waythey preferred journalistic content with an official certification, such as a certificate from governmental offices.

Further, participants mentioned trust often. This refers to the degree of confidence in the existing media news content. They mentioned that a well-known media brand or a journalist's reputation tended to enhance their trust. Even in cases in which they could not validate the contents' sources, an expert or an official institution's certification fostered their confidence. Finally, providing a label of original journalistic content was also mentioned frequently. A common opinion among all participants was that, in general, they valued a label issued by an official media association that regulated the journalistic contents' originality and quality. They believed that this effort would improve journalism's quality. For them, such a label could be considered an official certificate that would increase their confidence and to some extent, reduce false news' dissemination. However, some participants expressed concerns about the cost associated with such a labelling control mechanism, as they believed that it would increase the cost, but might not encourage readers to consume 
more contents significantly. In summary, while establishing a label would promote both the quality of journalistic content and increase the readership's trust, the cost remained an issue. Among all types of labels, labels united media associations or governmental authorities granted were perceived as the most reliable and trustworthy sources.

Based on the focus group discussions, we created a list of trust indicators, as shown in Table 2 . These indicators covered measurements of the specifications of media and journalist, as well as the journalism content, which were then grouped into six categories, transparency, author, work methods, nature of content, source, and interactivity.

Table 2. Trust indicators

\begin{tabular}{|c|c|c|}
\hline Category & Indicator & Measurement \\
\hline \multicolumn{3}{|c|}{ Transparency } \\
\hline & Independence & The media is independent of any external organizations \\
\hline & Transparency & $\begin{array}{l}\text { Clearly indicates the type of content (sponsored, paid) and includes } \\
\text { effective practices for posting clarifications and corrections in a } \\
\text { transparent manner }\end{array}$ \\
\hline & Editorial policy & Online and public editorial policies \\
\hline & Source and owners & Make the media's funding and the owner's name public \\
\hline & Ethics & The media follows ethical rules \\
\hline & Leaders and conflict interest & Make the leader's associations and conflicts of interest public \\
\hline \multicolumn{3}{|r|}{ 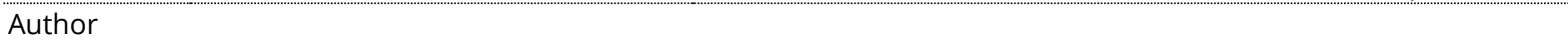 } \\
\hline & Experience and reputation & Ability to consult the history of each author's articles \\
\hline & Author's name & The author's name is published on the article \\
\hline & Bio, contact details & The author's bio and contact information are published \\
\hline \multicolumn{3}{|c|}{ Work methods } \\
\hline & Compliance with the code of ethics & The profession's code of ethics is respected \\
\hline & Working methods & The author's working methods are available for examination \\
\hline & Justification of author's choices & The author has justified his choices publicly \\
\hline \multicolumn{3}{|c|}{ Nature of content } \\
\hline & Credibility & The titles and content are not misleading \\
\hline & Perspective & The editors take different perspectives into account \\
\hline & Clarification & There is an efficient mechanism to clarify changes \\
\hline & Content types & $\begin{array}{l}\text { Prioritization of subjects by writing, mention of the article's type } \\
\text { (opinion, investigation, etc.) }\end{array}$ \\
\hline & Number of characters & Number of characters in the title, summary, and content \\
\hline & Metadata of documents & CMS Metadata Fields used to Maximize SEO \\
\hline & Originality of content & Similarity to the author's article on the Internet \\
\hline \multicolumn{3}{|l|}{ Sources } \\
\hline & Local sources & The content is checked against local news \\
\hline & Number of interviews and citations & The number of interviews and citations are mentioned in the article \\
\hline & Number of sources & The number of sources is mentioned in the article \\
\hline & Reference to sources & Sources from public resources \\
\hline \multicolumn{3}{|c|}{ Interactivity } \\
\hline & Interactivity & Ability to provide feedback \\
\hline & Interactivity with readers & Ability to interact with the author through the comments \\
\hline
\end{tabular}

\section{TRUST LABELLING SYSTEM IMPLEMENTATION AND EVALUATION}

\section{Labelling Distribution System Process Flow}

Before implementing the application, we designed a labelling distribution process flow (as shown in Figure 3) to help us define the actors involved and the functions necessary, as well as the way actors interact with the system. Our process included five actors: 


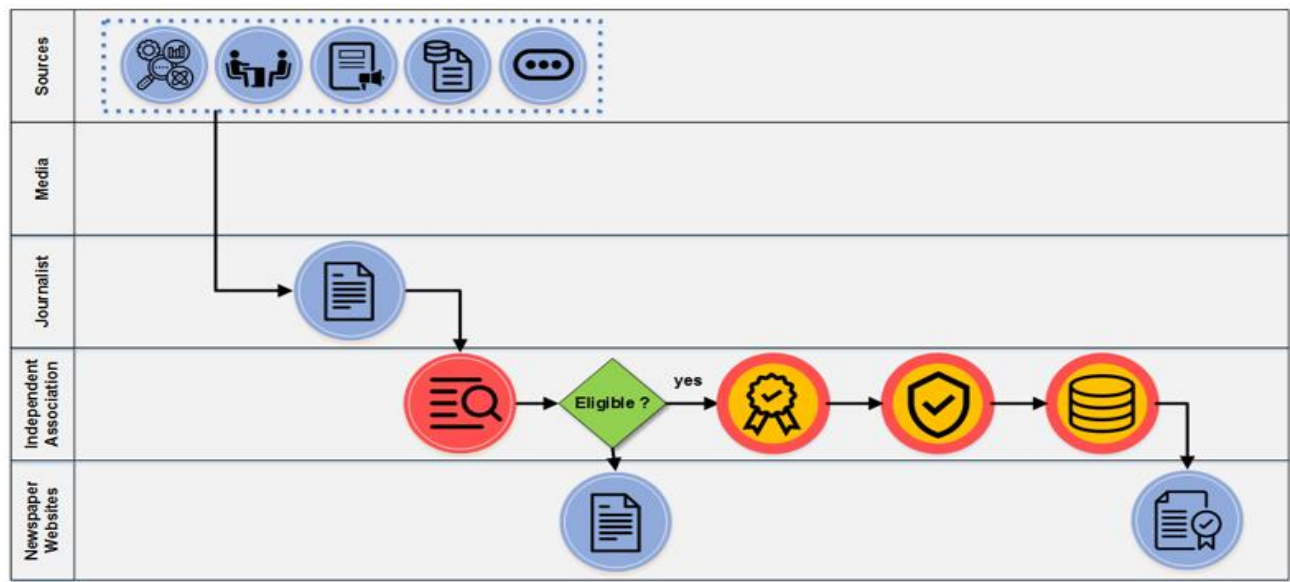

Figure 3. Labelling distribution process flow

1. Source: The source of the content used in the journalistic article, such as analysis and investigation, interviews, press communication.

2. Media: Designates any means of distributing, disseminating, or communicating works, documents, or written, visual, audio, or audiovisual messages. In this study, we examined ESH Medias (n.d.), which owns several newspaper brands, such as Le Nouvelliste (n.d.), Arcinfo (n.d.), La Côte (n.d.).

3. Journalist: The person who collects, verifies, writes, and distributes information on any type of media.

4. Independent media association: An authority association generates and distributes the certification of trust to the media and journalistic articles. This association holds a secure online server that provides the trust label to the journalistic content.

5. Newspaper website: The place to publish journalistic content, which is generated with a Content Management System (CMS).

As shown in Figure 3, once a journalist writes a news article, the system requires the author to conduct a self-assessment of the content according to a predefined trust indicator. Then, the content of the news article, together with the self-assessment, are submitted to the chief editor for a final decision about issuing the trust label. When the chief editor validates a news article, the application generates a label in QR Code format that contains a unique article identification automatically. In the meanwhile, all information about the news article evaluations is recorded in a secure database. To protect our trust label from malicious copying, as well as the server from malicious attacks, we applied the same methodologies to resolve security issues. Finally, the journalistic article is published on the press website with the label. The reader may scan the QR code and verify the information provided on the labelling system to validate the article's content.

\section{System Demonstration and Evaluation}

The following figures show the interfaces of the trust labelling distribution web-based application, which was developed using such programming languages as PHP, and JavaScript with the MYSQL database. Our program contains three types of functions for three different users: 1) journalist, content creation, and selfassessment; 2) editor, evaluation, and labelling distribution, and 3) reader, label traceability.

Specifically, our system allows journalists to create and/or assess a news article when they log into the system, as shown on the Figure 4. When writing a new article, the journalist must enter a set of information, such as the title, summary, and body of the news content. Then, the system generates a unique identity for this article automatically. Once an article has been created, the journalist may begin the self-assessment with the predefined trust indicators. For example, the algorithm in a function we used to detect the originality of the journalist's content retunes all plagiarism detection results with similar degrees, which allows us to understand the sources of similar articles on the web. Finally, our system gives a weight-based score for each trust indicator evaluation from the journalist, and the total score is finally submitted to the editor to decide whether to grant a label. 

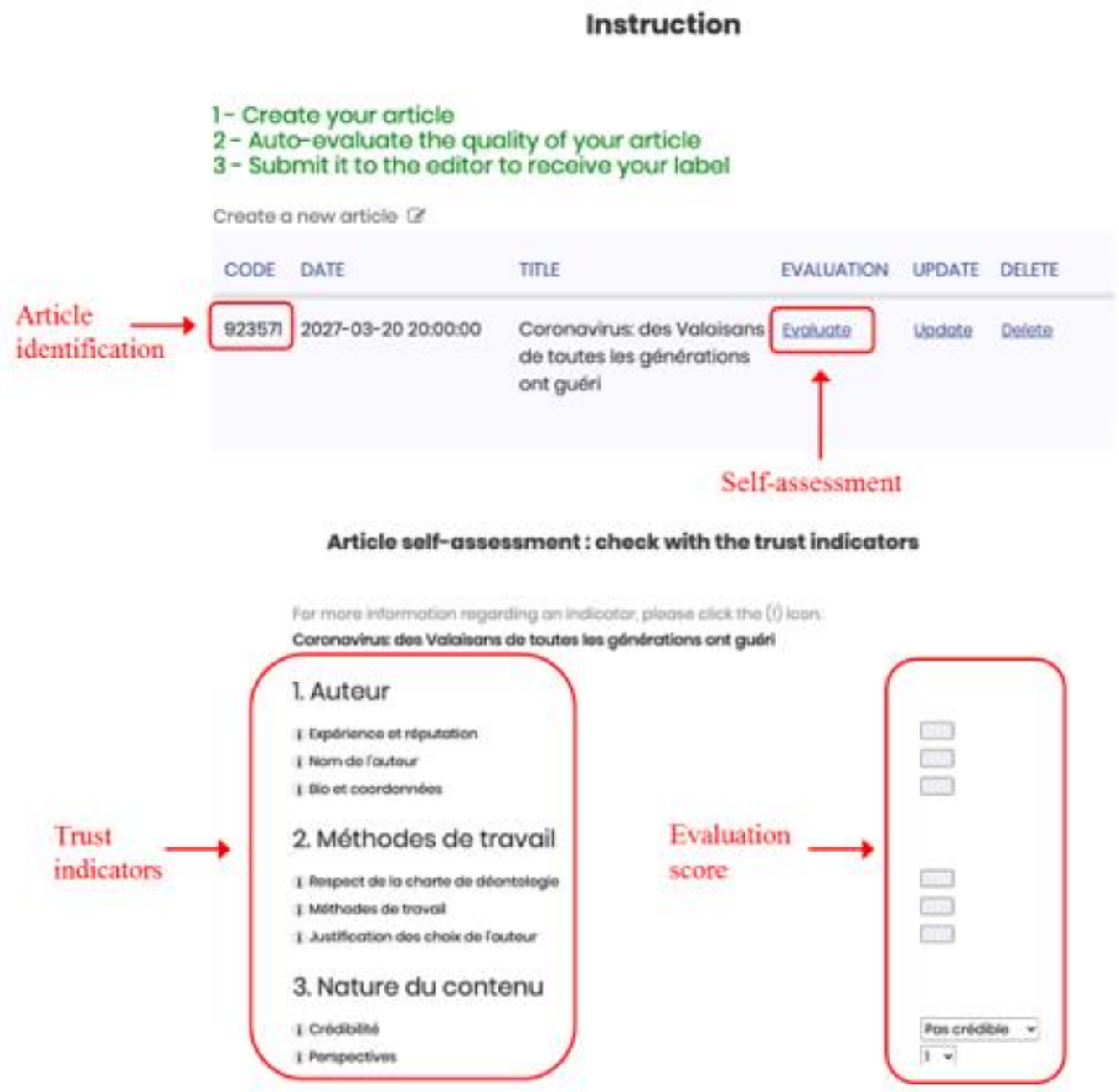

Figure 4. News articles creation and self-assessment

The interface shown on the Figure 5 is designed for newspaper company's editor. All news articles with the journalists' self-assessment results are displayed for the chief editor's review. A variety of information can be found on this page, such as the details of the journalist's evaluation for each indicator, the news article's content, and the number of readers' views and shares on social networks. With all of this information ready to hand, the chief editor can easily make the final decision readers. Once the positive decision has been made, the editor then assigns a QR code to the article selected and sends a confirmation to the corresponding journalist to inform him/her that the article has been granted a digital trust label.

Once the news article is released, when readers wish to examine its validation, they can scan the QR code with their mobile phone to obtain the article's unique identification number. Rather than showing the site URL and redirecting to the article page, our application shows only an identification code that consists of numbers and letters. Then, we ask readers to go to our official labelling page and enter this identification code for the verification information (shown on the Figure 6). We designed the application in this way for safety reasons, because firstly, the QR code is not encrypted, and anyone can generate this code and place it anywhere. Second, potential attackers could create a similar website that pretends to be the official one, but actually publishes false news and misinformation. In fact, it is usually difficult for readers to detect the website on which they are browsing, and rely only on its appearance to identify it, which will lead to security risks (Buber et al., 2017). Finally, once the application recognizes the identification from the QR code label the readers provide they can obtain the article's historical record to trace the news information. 


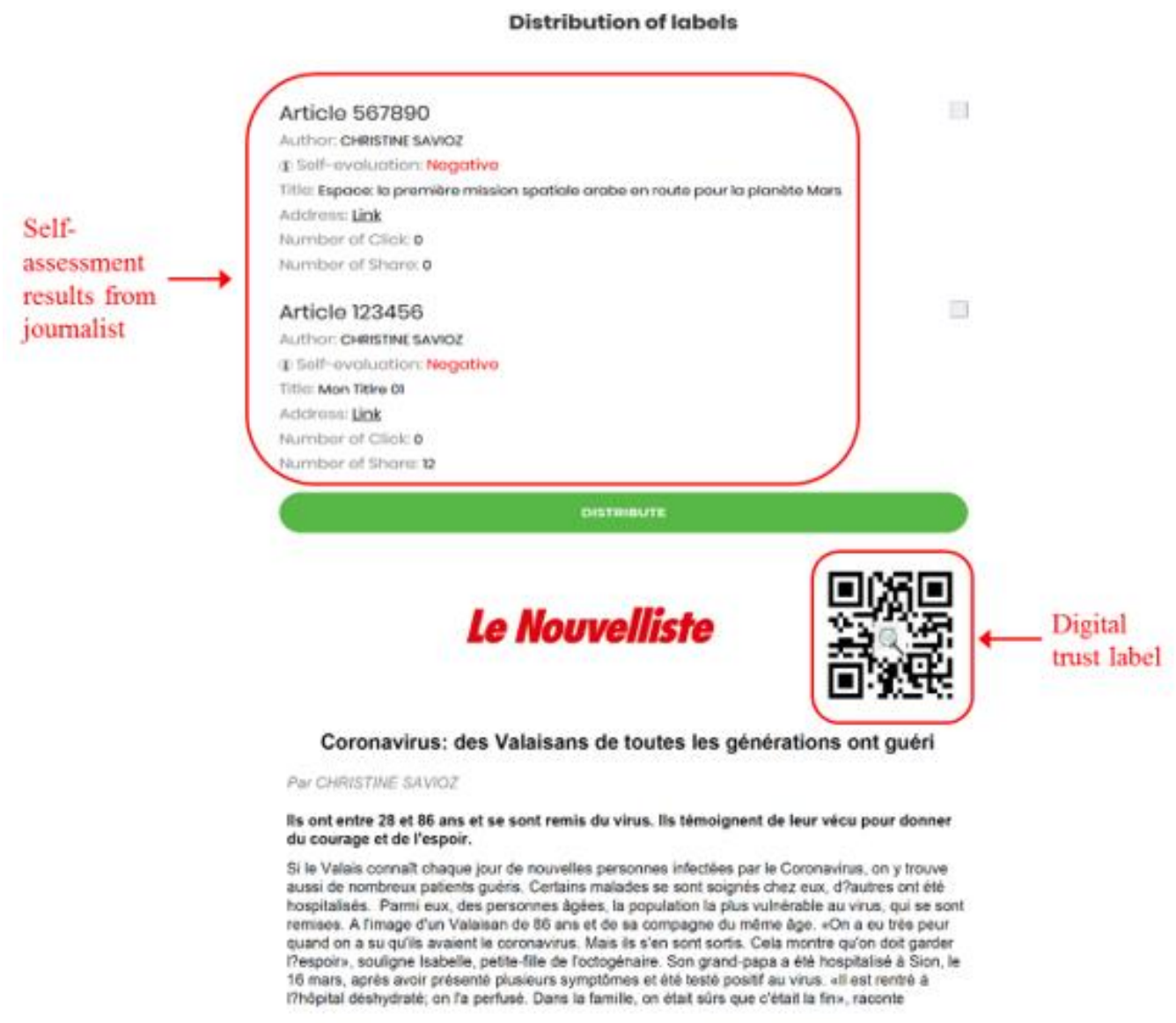

Figure 5. Labelling distribution and news article with digital trust label

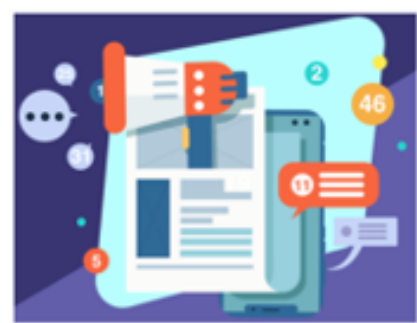

Article Code

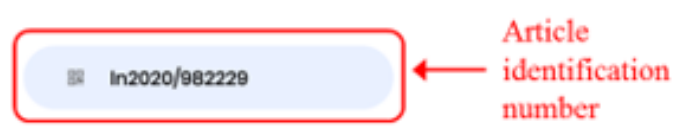

suBMrT

Article Traceability

\begin{tabular}{|c|}
\hline CARISINI SAVOZ \\
\hline Publication Date \\
\hline $2020-00-241846.21$ \\
\hline UR:: \\
\hline httpa//mwwlonouvelliste oh/articlos/v \\
\hline Titio: \\
\hline Adroport de Sionc les pilotes amoteurs \\
\hline Summary: \\
\hline $\begin{array}{l}\text { Après des mois dopposition la Contéc } \\
\text { do fobroport do Sion a parler anglais. }\end{array}$ \\
\hline
\end{tabular}

\section{CO TO THE OFFCLAL ARTCLE PACE}

Figure 6. Reader interface and article traceability 
We invited seven journalism experts and conducted individual interviews with them to test and evaluate the application. These experts included journalists and editors from three leading newspaper companies in Switzerland. During the interviews, we asked about the users' experiences with respect to how easy the application was to use and their perspectives about its feasibility. Most of the experts agreed that it was an interesting approach to distribute the trust label of journalist contents, and that the study in general could play a useful role to meet the challenges of quality digital content's visibility and public trust in news. However, they also expressed concerns about the time required to verify content each time in the early stage of using this system and proposed a global label for an entire media rather than for each content. Moreover, we asked their opinions about the process of tracing the content. The participants believed that readers' participation in verifying the label's authenticity can increase their trust in news content, and they also emphasized the importance of labels' visibility and easy identification in the application. At the end of the discussion, the experts believed that as more Swiss media and newspapers participate, the application should be able to serve as a feasible solution to verify journalistic contents' certification digitally. In addition, the labelling trust indicators should be a common format and based on the professional ethics of the journalism.

\section{CONCLUSIONS}

In this paper, we described an innovative digital labelling solution to certify journalistic contents, which could both promote the quality of journalistic content and increase the readership's trust. To accomplish this objective, we adopted a design science approach: Firstly, we conducted several focus group discussions to analyse such a solution's effect on readers' trust in news contents. Then, based on the results of discussion, we created a list of trust indicators to measure the media and journalist specifications and the content quality. Most importantly, we designed and developed an online system to distribute the trust labelling with the defined indicators and built a process of journalistic content traceability with the readers' interaction. Our solution provided guidelines to assure the quality of news content and contribute to the establishment of a trust mechanism with readers.

Future research could include both application platform deployment and security technology enhancements. We intend to attract more media and newspapers companies to participate through the promotion of the national united media associations. Institutions trusted widely, such as authoritative news organizations or governmental authorities, could deploy such a digital application platform. Therefore, it is important to precise that a digital application by a governmental authority seems to be well accepted by the younger readers. This feeling is not shared by older readers or journalists that would perceive a real attack on their independence. Moreover, it might be useful to apply blockchain technologies, particularly a private blockchain (Dinh et al., 2017), to reduce the risk from potential attacks while ensuring that the digital label is not tampered with maliciously. In addition, it could be interesting to also include indicators on equality, such as gender parity or the legitimacy of the author. This last point would make it possible to assess whether the author is legitimate to talk about a subject thanks to socio-demographic criteria. This has an impact on the potential quality of a journalistic work.

Author contributions: All authors were involved in concept, design, collection of data, interpretation, writing, and critically revising the article. All authors approve final version of the article.

Funding: The work described in this paper was supported by the Initiative for Media Innovation (IMI) funding, which is based on Media Center, EPFL, Lausanne, Switzerland.

Declaration of interest: Authors declare no competing interest.

Data availability: Data generated or analysed during this study are available from the authors on request.

\section{REFERENCES}

Abras, C., Maloney-Krichmar, D., \& Preece, J. (2004). User-centered design. In W. S. Bainbridge (Ed.), Berkshire encyclopedia of human-computer interaction (pp. 445-456). SAGE.

Arcinfo. (n.d.). Arcinfo.ch, actualités des cantons de Neuchâtel et du Jura [Arcinfo.ch, news from the cantons of Neuchâtel and Jura]. https://www.arcinfo.ch/ 
Barthel, M., Mitchell, A., \& Holcomb, J. (2016). Many Americans believe fake news is sowing confusion. https://www.pewresearch.org/journalism/2016/12/15/many-americans-believe-fake-news-is-sowingconfusion/

Bennett, M., \& Brandt, S. (2019). Newsguard: Fighting misinformation with nutrition labels for news. https://ylai.state.gov/newsguard-fighting-misinformation/

Boulay, E. (2018). RSF and its partners unveil the journalism trust initiative to combat disinformation. https://rsf.org/en/news/rsf-and-its-partners-unveil-journalism-trust-initiative-combat-disinformation

Bozarth, L., \& Budak, C. (2020). Toward a better performance evaluation framework for fake news classification. Proceedings of the International AAAl Conference on Web and Social Media (pp. 60-71).

Buber, E., Demir, O., \& Sahingoz, O. K. (2017). Feature selections for the machine learning based detection of phishing websites. Proceedings of 2017 International Artificial Intelligence and Data Processing Symposium (pp. 1-5). https://doi.org/10.1109/IDAP.2017.8090317

Buntain, C., \& Golbeck, J. (2017). Automatically identifying fake news in popular Twitter threads. Proceedings of the 2017 IEEE International Conference on Smart Cloud (pp. 208-215). https://doi.org/10.1109/SmartCloud.2017.40

Davison, W. P. (1983). The third-person effect in communication. Public Opinion Quarterly, 47(1), 1-15. https://doi.org/10.1086/268763

Deschamps, T. (2018). Google announces 'Google News Initiative' to help quality journalism in digital age. http://canoe.com/technology/google-announces-google-news-initiative-to-help-quality-journalism-indigital-age

Dinh, T. T. A., Wang, J., Chen, G., Liu, R., Ooi, B. C., \& Tan, K.-L. (2017). Blockbench: A framework for analyzing private blockchains. Proceedings of the 2017 ACM International Conference on Management of Data (pp. 1085-1100). https://doi.org/10.1145/3035918.3064033

Dinkov, Y., Ali, A., Koychev, I., \& Nakov, P. (2019). Predicting the leading political ideology of YouTube channels using acoustic, textual, and metadata Information. arXiv preprint arXiv:1910.08948. https://doi.org/10.21437/Interspeech.2019-2965

ESH Média. (n.d.). ESH Médias, agir ensemble dans nos régions [ESH Médias, acting together in our regions]. https://www.eshmedias.ch/

Hevner, A., March, S. T., Park, J., \& Ram, S. (2004). Design science in information systems research. MIS Quarterly, 28(1), 75-105. https://doi.org/10.2307/25148625

Iannucci, R. (2017). News or opinion? Online, it's hard to tell. https://www.poynter.org/ethics-trust/2017/newsor-opinion-online-its-hard-to-tell/

Knight Foundation. (2020). American views 2020: Trust, media, and democracy. https://knightfoundation.org/reports/american-views-2020-trust-media-and-democracy

Krouwer, S., Poels, K., \& Paulussen, S. (2020). Moving towards transparency for native advertisements on news websites: A test of more detailed disclosures. International Journal of Advertising, 39(1), 51-73. https://doi.org/10.1080/02650487.2019.1575107

La Côte. (n.d.). La Côte, actualités régionales de la Côte [La Côte, regional news from Nyon, Rolle, Aubonne, and Morges]. https://www.lacote.ch/

Lacey, A., \& Luff, D. (2007). Qualitative research analysis. The NIHR RDS for the East Midlands/Yorkshire \& the Humber. https://www.rds-yh.nihr.ac.uk/wp-content/uploads/2013/05/9_Qualitative_Data_Analysis_ Revision_2009.pdf

Le Nouvelliste. (n.d.). Le Nouvelliste, actualités du Valais [Le Nouvelliste, news from Valais]. https://www.lenouvelliste.ch/

Lehrman, S. (2016). Trust project summit report. https://n36.08b.myftpupload.com/wpcontent/uploads/2019/03/Summit_Report_Hearst20May_ms_sl-1.pdf

Lewis, S. C., Holton, A. E., \& Coddington, M. (2014). Reciprocal journalism: A concept of mutual exchange between journalists and audiences. Journalism Practice, 8(2), 229-241. https://doi.org/10.1080/17512786.2013.859840

Liu, Z., Shabani, S., Balet, N. G., \& Sokhn, M. (2019). Detection of satiric news on social media: analysis of the phenomenon with a French dataset. Proceedings of the 28th International Conference on Computer Communication and Networks (pp. 1-6). https://doi.org/10.1109/ICCCN.2019.8847041 
Liu, Z., Shan, J., Delaloye, M., Piguet, J. G., \& Glassey, N. B. (2020). The role of public trust and media in managing the dissemination of COVID-19-related news in Switzerland. Journalism and Media, 1(1), 145-158. https://doi.org/10.3390/journalmedia1010010

Newman, N., \& Fletcher, R. (2017). Bias, bullshit and lies: Audience perspectives on low trust in the media. http://reutersinstitute.politics.ox.ac.uk/our-research/bias-bullshit-and-lies-audience-perspectives-lowtrust-media/. https://doi.org/10.2139/ssrn.3173579

Nørregaard, J., Horne, B. D., \& Adali, S. (2019). Nela-gt-2018: A large multi-labelled news dataset for the study of misinformation in news articles. Proceedings of the International AAAl Conference on Web and Social Media (pp. 630-638).

Ozbay, F. A., \& Alatas, B. (2020). Fake news detection within online social media using supervised artificial intelligence algorithms. Physica A: Statistical Mechanics and its Applications, 540(123174), 1-17. https://doi.org/10.1016/j.physa.2019.123174

Peacock, C., Masullo, G. M., \& Stroud, N. J. (2020). What's in a label? The effect of news labels on perceived credibility. Journalism. https://doi.org/10.1177/1464884920971522

Publico. (2018). This is how the editorial transparency calculator of 'Público' works. https://blogs.publico.es/publico/2018/10/10/this-is-how-the-editorial-transparency-calculator-ofpublico-works/

Shabani, S., \& Sokhn, M. (2018). Hybrid machine-crowd approach for fake news detection. Proceedings of the 2018 IEEE 4th International Conference on Collaboration and Internet Computing (pp. 299-306). https://doi.org/10.1109/CIC.2018.00048

Shu, K., Sliva, A., Wang, S., Tang, J., \& Liu, H. (2017). Fake news detection on social media: A data mining perspective. ACM SIGKDD Explorations Newsletter, 19(1), 22-36. https://doi.org/10.1145/3137597.3137600

Srivastava, A., \& Thomson, S. B. (2009). Framework analysis: A qualitative methodology for applied policy research, Journal of Administration Governance, 4(2), 72-79.

Starbird, K. (2017). Examining the alternative media ecosystem through the production of alternative narratives of mass shooting events on Twitter. Proceedings of the International AAAl Conference on Web and Social Media (pp. 230-239).

Stefanov, P., Darwish, K., Atanasov, A., \& Nakov, P. (2020). Predicting the topical stance and political leaning of media using tweets. Proceedings of the 58th Annual Meeting of the Association for Computational Linguistics (pp. 527-537). https://doi.org/10.18653/v1/2020.acl-main.50

Stelter, B. (2018). This start-up wants to evaluate your news sources. https://money.cnn.com/2018/03/04/media/newsguard-steven-brill-gordon-crovitz/index.html

Van Zandt, D. (2021). Media bias/fact check. https://mediabiasfactcheck.com/about/

Wang, W. Y. (2017). "Liar, liar pants on fire": A new benchmark dataset for fake news detection. Proceedings of the 55th Annual Meeting of the Association for Computational Linguistics (pp. 422-426). https://doi.org/10.18653/v1/P17-2067

Zhang, A. X., Ranganathan, A., Metz, S. E., Appling, S., Sehat, C. M., Gilmore, N., Adams, N. B., Vincent, E., Lee, J., Robbins, M., Bice, E., Hawke, S., \& Karger, D. (2018). A structured response to misinformation: Defining and annotating credibility indicators in news articles. Proceedings of The Web Conference 2018 (pp. 603612). https://doi.org/10.1145/3184558.3188731

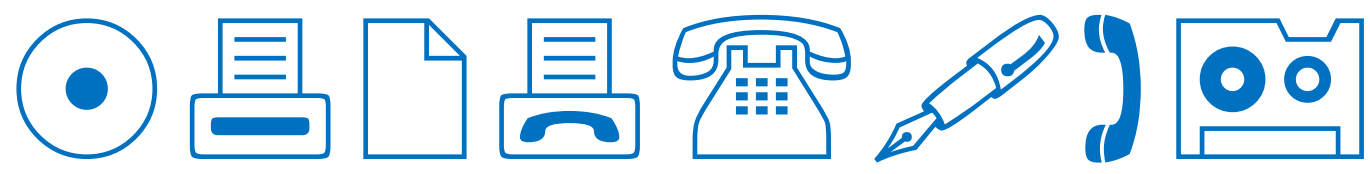

